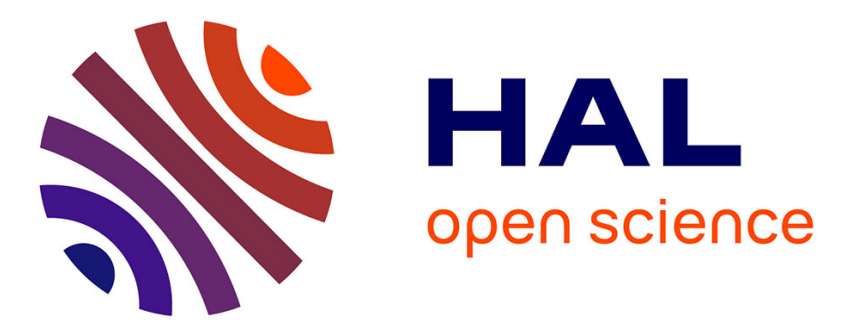

\title{
Mesospheric temperature inversion and gravity wave breaking
}

\author{
Alain Hauchecorne, Marie-Lise Chanin, Richard Wilson
}

\section{To cite this version:}

Alain Hauchecorne, Marie-Lise Chanin, Richard Wilson. Mesospheric temperature inversion and gravity wave breaking. Geophysical Research Letters, 1987, 14 (9), pp.933-936. 10.1029/GL014i009p00933 . insu-03123428

\section{HAL Id: insu-03123428 \\ https://hal-insu.archives-ouvertes.fr/insu-03123428}

Submitted on 28 Jan 2021

HAL is a multi-disciplinary open access archive for the deposit and dissemination of scientific research documents, whether they are published or not. The documents may come from teaching and research institutions in France or abroad, or from public or private research centers.
L'archive ouverte pluridisciplinaire HAL, est destinée au dépôt et à la diffusion de documents scientifiques de niveau recherche, publiés ou non, émanant des établissements d'enseignement et de recherche français ou étrangers, des laboratoires publics ou privés. 


\section{MESOSPHERIC TEMPERATURE INVERSION AND GRAVITY WAVE BREAKING}

A. Hauchecorne, M.L. Chanin, and R. Wilson

Service d'Aéronomie du CNRS, BP 3, 91371 Verrières le Buisson, France

\begin{abstract}
More than 500 nightly mean temperature profiles have been obtained since 1981 by two Rayleigh lidars located in south of France $550 \mathrm{~km}$ apart. In the mesosphere a temperature inversion, a feature persisting for several days, is frequently observed simultaneously at both sites. From a statistical study of the inversion characteristics, it is shown that its altitude ranges from $55-72 \mathrm{~km}$ in winter to $70-83 \mathrm{~km}$ in summer, while its probability of occurrence presents a semi-annual variation with a maximum higher in winter than in summer and a minimum lower in May than in september. The seasonal variation of the temperature inversion is shown to be very similar to that of the MST radar echoes in the mesosphere associated to turbulent layers generated by the breaking of gravity waves. A crude estimate of the amplitude growth with height of a gravity wave in the presence of an inversion layer indicates that the wave will break preferably inside and above this layer. The persistence of a temperature inversion during several days, with amplitude as large as $40 \mathrm{~K}$, is tentatively explained by the heating of the turbulent layers generated by the continuous breaking of gravity waves above the secondary minimum of temperature.
\end{abstract}

\section{Introduction}

The zonal mean circulation in the upper mesosphere is very different from the circulation predicted if a radiative equilibrium of the atmosphere is assumed. At the mesopause level the zonal winds are easterly in winter and westerly in summer, whereas the radiative equilibrium would induce strong winds in the opposite direction (Schoeberl and Strobel, 1978). The winter mesopause is also much warmer in the real atmosphere than in the radiative one. The role of the gravity wave dissipation to maintain the observed mesospheric circulation has been pointed out by many authors during the latest years (Lindzen, 1981 ; Matsuno, 1982; Holton, 1982 ; Schoeberl et al., 1983). It is now well recognized that wave transience and dissipation in the mesosphere are responsible for the observed thermodynamical structure and circulation.

However all models assume a regular decrease of temperature from the stratopause to the mesopause while our Rayleigh lidars measurements, taken on a regular basis since 1981, display quite frequently a secondary maximum of temperature. As far back as the sixties, this anomaly was already observed around $75 \mathrm{~km}$ by rocket measurement. Such a result was reported by Schmidlin (1976) but without explanation. More recently local density deficiencies were observed

Copyright 1987 by the American Geophysical Union.

Paper number 716619 .

$0094-8276 / 87 / 007 L-6619903.00$ from reentry data of the US space shuttle around the same altitude (Champion, 1986). Such density anomalies are associated with layers of temperature inversion.

The goal of this paper is to present a statistical analysis of this phenomenon by using more than 500 lidar temperature profiles, and to show that it is consistent with the breaking of gravity waves in the mesosphere.

\section{Experimental Evidence}

Rayleigh lidars provide temperature profiles from 30 to $90 \mathrm{~km}$ with a good vertical resolution (Hauchecorne and Chanin, 1980 ; Chanin and Hauchecorne, 1984). If the data are integrated during a few hours, short term variations due to gravity wave perturbations tend to vanish and the resulting temperature profile is representative of the mean state of the atmosphere above the lidar. Such profiles obtained in December 1986 during 5 consecutive nights by the Rayleigh lidar located at Biscarrosse $\left(44^{\circ} \mathrm{N}, 1^{\circ} \mathrm{W}\right)$ are shown in Figure 1. In the mesosphere these profiles are characterized by a minimum of temperature near $70 \mathrm{~km}$, a strong positive gradient above, a secondary maximum near $75-80 \mathrm{~km}$ (up to $40 \mathrm{~K}$ warmer than the minimum) and scattered variations at the top of the profile. It should be noted that a $40 \mathrm{~K}$ increase in temperature is associated with a 17 \& decrease in density. In this example the inversion layer persists at the same altitude during a period of 5 days what is typical of our observations. A profile obtained on December 1 , 1986 by the second lidar located at the Haute Provence Observatory (hereafter OHP, $44^{\circ} \mathrm{N}, 6^{\circ} \mathrm{E}$ ) (Figure 2) shows an inversion layer at the same altitude as in the Biscarrosse profile taken simultaneously, what indicates a horizontal extension of at least $550 \mathrm{~km}$ for this layer. The short term stability of the temperature inversion may be studied by comparing hourly averaged profiles during a night. This has been done for the night of December 1, 1986 at OHP (Figure 3). Due to the short time of integration, these profiles are modulated by the presence of internal gravity waves. It is not the purpose of this paper to study the gravity waves for themselves as observed from lidar data and for that purpose the reader may refer to Chanin and Hauchecorne (1981; 1987). The inversion layer is visible in all the hourly profiles between 70 and $75 \mathrm{~km}$ with a variable amplitude. This example shows that the inversion layer persists during the night and thus should not be interpreted as a tidal effect. Furthermore such a phenomenon is not only observed during winter : Figure 4 shows two profiles obtained in July 1986 by the OHP lidar. It thus appears that the existence of an inversion layer is not related to the propagation of planetary waves through the middle atmosphere, as they are blocked by the easterly stratospheric winds in summer. 


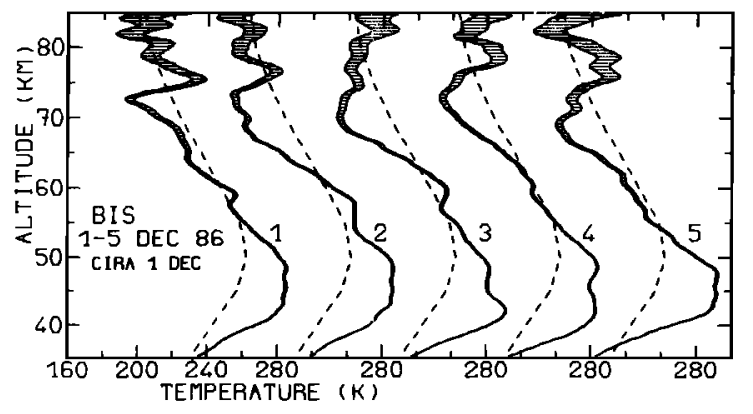

Fig. 1 Nightly mean temperature profiles at Biscarrosse from December 1 to December 5, 1986. The error bars $( \pm 1 \sigma)$ are indicated by the shaded area. The CIRA 1972 profile is shown for comparison (dotted line). Perturbations with vertical wavelengths shorter than $1.5 \mathrm{~km}$ have been filtered.

\section{Statistical Studies}

The OHP lidar has provided a mean temperature profile for each night of clear sky conditions since June 1981 and more than 500 profiles are available to characterize the mesospheric inversion on a statistical basis. In order to perform this study, we define a criterion for the existence of an inversion layer which is an increase of temperature above the first minimum larger than a specified value ( $10 \mathrm{~K}$ or $20 \mathrm{~K}$ ) with an accuracy better than $5 \mathrm{~K}$. Figure 5 shows from all the profiles from June 1981 to September 1986 for which an inversion has been detected, the altitude of the minimum of temperature, versus the day of the year. The number of observed inversions is large in winter, from December to February, at altitudes ranging from 55 to $72 \mathrm{~km}$. In summer, from June to September, the density of observations is lower and the altitudes are mainly concentrated between 70 and $83 \mathrm{~km}$; MarchApril and October-November appear as periods of transition between the winter and the summer regimes : only two inversions are observed in May. It should be noted that the seasonal variation of the altitude of the inversion is very similar to the seasonal variation of the MST radar echoes in the mesosphere shown for instance by Balsley and Ecklund (1984) for the Poker Flat radar; the altitude of the maximum of the radar echoes is about $5 \mathrm{~km}$ higher than the altitude of the inversion. These authors consider that the radar echoes are due to turbulence layers generated by the breaking of gravity waves. Such a result seems to indicate that the two phenomena have the same origin and that the temperature inversion is directly related to the breaking of

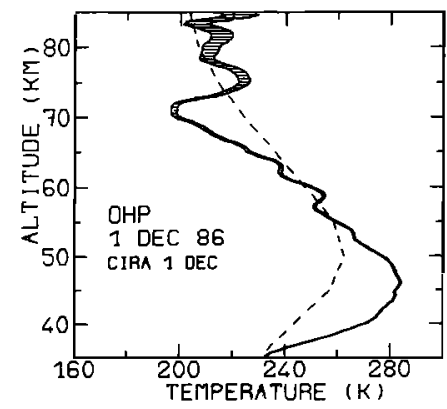

Fig. 2 Nightly mean temperature profile at OHP on December 1, 1986.

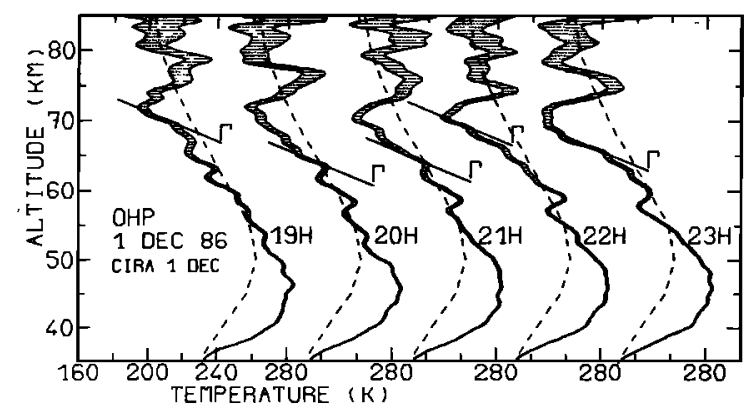

Fig. 3 Hourly mean temperature profiles on December 1, 1986 at OHP. The adiabatic lapse rate $\Gamma$ is represented for comparison in the layer of strong negative lapse rates.

gravity waves generating turbulence above the minimum of temperature. In addition, the seasonal variation of the altitude of the inversion is similar to the one predicted for the altitude of the breaking level of gravity waves (Lindzen, 1981). Figure 6 shows the seasonal variation of the probability of occurrence of a mesospheric inversion. A strong maximum is observed in December-January (with respectively 70 and 50 \% of probability with the $10 \mathrm{~K}$ and $20 \mathrm{~K}$ criteria) and a secondary maximum in July-August (with respectively 35 and 10 of probability with the $10 \mathrm{~K}$ and $20 \mathrm{~K}$ criteria). The May minimum is more pronounced that the one of September. These two minima occur at the time of the two minima of the stratospheric winds above France ; the observed variation in the occurrence of the mesospheric inversion is quite similar to the semiannual variation of the gravity waves activity in the upper mesosphere first suggested by Thomas et al. (1984) to explain the equinoctial enhancements of the mesospheric ozone and after confirmed later by radar observations (Meek et al., 1985 ; Vincent and Fritts, 1987). If we assume that the inversion layer is produced by the breaking of gravity waves due to a convective instability, we should expect near adiabatic lapse rates to exist just below the level of breaking. Actually such lapse rates are commonly observed below the inversion layer in the hourly temperature profiles as shown in Figure 3. All these elements lead us to conclude that the mesospheric inversion is directly related to the breaking of gravity waves above the secondary minimum of temperature.

\section{Relationship With Gravity Waves Saturation}

We present now a possible explanation for the persistence of an inversion layer during several
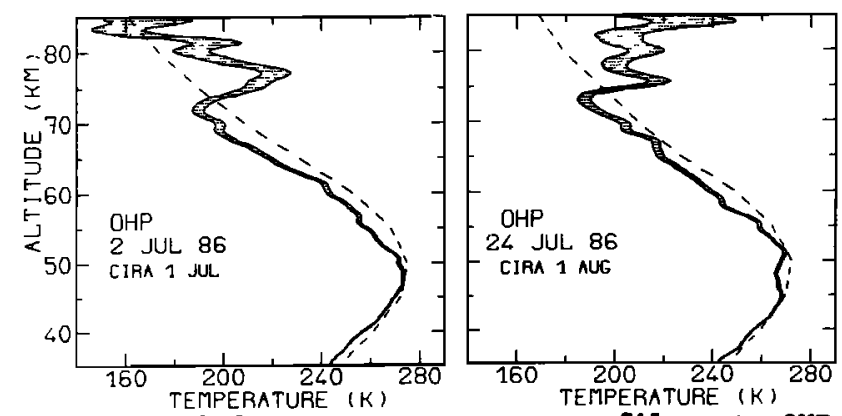

Fig. 4 Nightly mean temperature profiles at OHP on July 2, and July $24,1986$. 


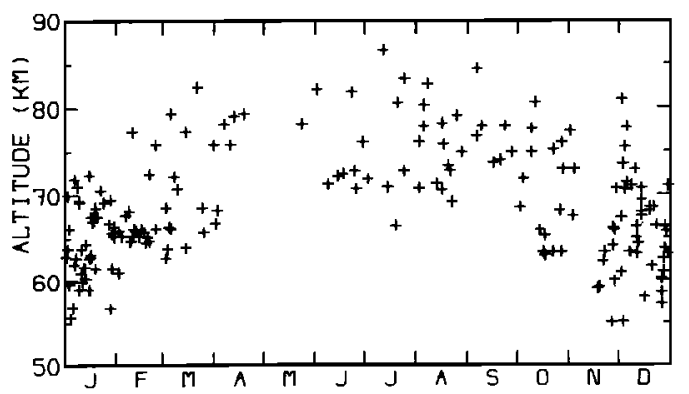

Fig. 5 Altitude of the secondary minimum of temperature versus the day of the year for all OHP profiles from June 1981 to September 1986 for which a temperature inversion has been detected (10 $\mathrm{K}$ criterion).

days. We will show that the breaking of gravity waves should occur preferably inside and above the inversion layer and that the dissipation of the waves could maintain a quite stable temperature inversion. For that purpose a crude estimation of the amplitude growth with height of a non-dissipating gravity wave will be compared to its saturation amplitude.

In the absence of dissipation the vertical momentum flux of a wave is conserved. This conservation may be written for a wave propagating in a two-dimensional atmosphere :

$$
\rho \overline{u^{\prime} w^{\prime}}=F_{0} \propto \rho_{0} e^{-z / H} \overline{u^{\prime} w^{\prime}}
$$

where $\rho$ and $\rho$ are the atmospheric densities at the altitude $z$ and $z=0, u^{\prime}$ and $w^{\prime}$ the horizontal and vertical wind perturbations due to the wave, $F$ the vertical momentum flux and $H$ the mean scale-height of the atmosphere. If we assume that

$$
f \ll \omega \ll N
$$

and using the short wavelength approximation

$$
2 \text { H k } \mathbf{z}_{\mathbf{z}} \gg 1
$$

where $f, \omega$ and $N$ are respectively the Coriolis, the wave and the Brunt-Vaísäla frequencies and $k_{2}$ the vertical wave number, the relation between $u^{2}$ and $w^{\prime}$ is reduced to

$$
w^{\prime}-\omega u^{\prime} / N
$$

The wave frequency is equal to:

$$
\omega=k_{x}(\bar{u}-c)
$$

where $k_{x}$ is the horizontal wave number, $\bar{u}$ the mean zonal wind and $c$ the horizontal phase speed of the wave. Introducing (4) and (5) into (1) we obtain :

$$
u^{\prime 2}=\frac{F_{0}}{\rho_{0} k_{x}} \frac{N e^{-z / B}}{\bar{u}-c}
$$

With the hypothesis (2) and (3), the temperature and wind perturbations $T^{\prime}$ and $u^{\prime}$ are related by :

$$
T^{\prime} \approx u^{\prime} \mathrm{NT} / \mathrm{g}
$$

where $T$ is the mean temperature and $g$ the acceleration of gravity. From (6) and(7) we obtain the estimation of the temperature perturbations :

$$
T^{\prime 2}=\frac{F_{0}}{\rho_{0} k_{x}} \frac{N^{3} e^{2 / R} T^{2}}{(\bar{u}-c) g^{2}}
$$

The amplitude of the wave may grow without dissipation up to the altitude where a condition of instability is met. If we assume that a convective instability occurs, which is a reasonable assumption considering the profiles shown in Figure 3, the wave induces an adiabatic temperature lapse rate. This gives:

$$
k_{z} T^{\prime} \simeq N^{2} T / g
$$

where $T^{\prime}$ is the saturation amplitude of the wave. With the hypothesis (2) and (3) $\mathrm{k}_{\mathrm{z}}$ is expressed as :

$$
k_{z}=\frac{k_{x} N}{\omega}=\frac{N}{\bar{u}-c}
$$

and the saturation amplitude expression is :

$$
\mathrm{T}^{\prime},{ }^{2} \approx \mathrm{N}^{2} \mathrm{~T}^{2}(\overline{\mathrm{u}}-\mathrm{c})^{2} / \mathrm{g}^{2}
$$

The ratio $R$ of the wave amplitude $T$ ' to its saturation value $T^{\prime}$ is obtained from (8) and (11) :

$$
R=\frac{T^{\prime}}{T^{\prime}} \approx\left[\frac{F_{0}}{\rho_{0} k_{x}} \frac{N e^{2 / B}}{(\bar{u}-c)^{3}}\right]^{1 / 2}
$$

A saturation of the wave occurs as soon as the ratio $R$ becomes greater than 1 . In addition to its exponential increase with height, $R$ increases with $N$ and with $1 /(\bar{u}-c)^{3}$. Thus it depends strongly on the mean temperature and wind profiles. Figure 7 shows a schematic description of the variation with height of these quantities in the case of a mesospheric inversion, for instance in winter. Considering the hourly profiles shown on Figure 3 we assume that the wave is near its saturation below the inversion. When the wave reaches the inversion layer, $N$ increases suddenly and, assuming that this layer corresponds to the region of decrease of the zonal wind above the westerly mesospheric jet, hypothesis that will be justified thereafter, $\bar{u}$ - $c$ decreases for a large range of $c$ values around 0 . A large increase of $R$ is obtained in the inversion layer and a strong super-saturation of the wave is expected. This wave deposits its momentum, decelerates the zonal wind (what justifies our hypothesis on the decrease of $\vec{u}$ in the inversion layer), and its breaking produces turbulence. As seen in Figure 7, the generation of turbulence occurs inside and above the inversion layer. The presence of turbulence above the minimum of temperature helps maintaining the inversion layer by two processes. The first one is the heating due to the viscous dissipation of

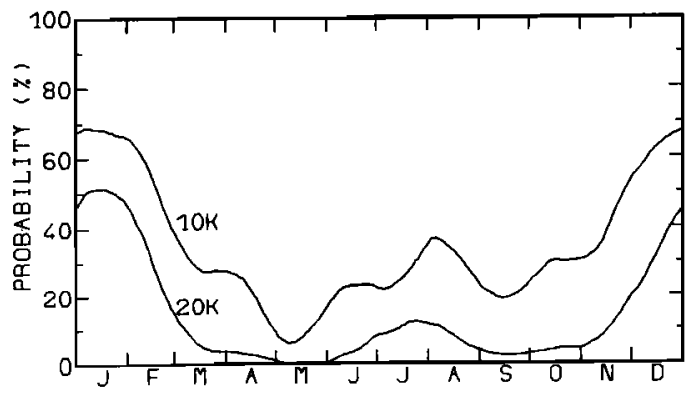

Fig. 6 Annual variation of the probability of occurrence of a mesospheric inversion for the $10 \mathrm{~K}$ and $20 \mathrm{~K}$ criteria. A \pm 30 days triangular filter has been applied to smooth the data. 


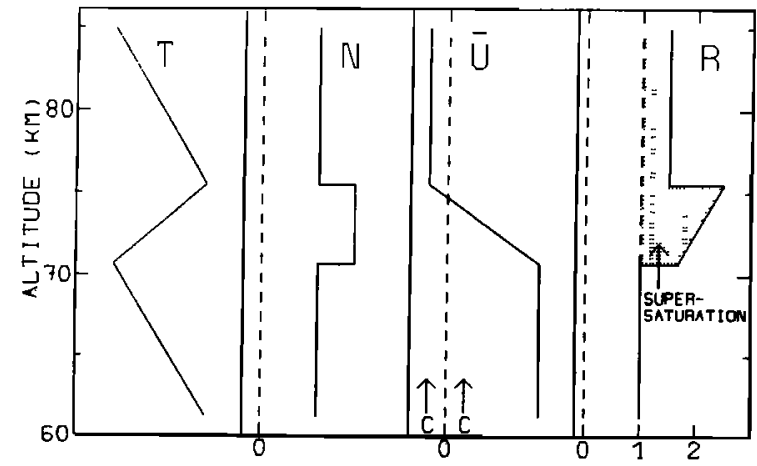

Fig. 7 Schematic representation of the vertical profiles of the mean temperature $T$, the Brunt-Valssala frequency $\mathrm{N}$, the mean zonal wind $\bar{u}$ and the ratio of saturation $R=T^{\prime} / T^{\prime}$, during a mesospheric inversion.

turbulent motions and the second one is the downward vertical heat flux from the upper layer to the Inversion layer due to the turbulent vertical mixing of the atmosphere. These two processes heat the inversion layer while the layer underlying the minimum of temperature remains non-turbulent and cold. The studies of the energy budget of the mesosphere (Ebel, 1984) have shown that these two processes are very efficient above $70 \mathrm{~km}$ and may contribute by a few tens of Kelvins per day to the heat budget of the upper mesosphere. It is then possible to explain by this mechanism how a temperature inversion layer, with an amplitude as large as $40 \mathrm{~K}$, persists during several days, by the continuous breaking of gravity waves occurring preferably in this layer.

\section{Conclusion}

Rayleigh lidar observations of the mesospheric temperature in south of France have shown the frequent existence of a temperature inversion, that persists during several days at the same altitude and exists simultaneously above the two lidar sites distant by $550 \mathrm{~km}$. The statistical characteristics of this inversion, obtained from more than 500 nightly mean profiles, are as follows :

- The altitude of the minimum of temperature has an annual variation with values ranging from 55 to $72 \mathrm{~km}$ in winter and from 70 to $83 \mathrm{~km}$ in summer ;

- The probability of occurrence of the temperature inversion has a semi-annual variation with a higher maximum in winter (70 \%) than in summer $(358)$ and a lower minimum in May than in September.

The comparison of the characteristics of the temperature inversion and of the MST radar echoes in the mesosphere, and a simple estimation of the amplitude growth with height of a gravity wave, lead us to conclude that the two phenomena have the same origin, that is to say the turbulent field generated by the breaking of gravity waves. This breaking occurs preferably above the secondary minimum of temperature and can maintain its existence during several days with an amplitude as large as $40 \mathrm{~K}$.

Acknowledgments. The authors are grateful to the technical staff of the lidar team for their help in operating the station in particular to J.P. SCHNEIDER, F. SYDA, J. BOURDARIE and G. BAIN who collected the data. They also acknowledge the helpful comments of $H$. LE TEXIER on the manuscript. This work was supported by CNRS, DRET and ETCA.

\section{References}

Basley, B.B., W.L. Ecklund and D.C. Fritts, VHF echoes from the Arctic mesosphere and lower thermosphere, Part I : Observations in "Dynamics of the middle atmosphere", Terra Scientific Publishing Company, Tokyo, 1984.

Champion, K.S.W., Middle atmosphere models and comparison with Shuttle reentry density data, Advances in Space Research, 6 , 1986.

Chanin, M.L. and A. Hauchecorne, Lidar observations of gravity and tidal waves in the stratosphere and mesosphere, J.Geophys. Res., 86, 9715-9721, 1981 .

Chanin, M.L. and A. Hauchecorne, Lidar studies of temperature and density using Rayleigh scattering, MAP Handbook, 13, 87-99, 1984.

Chanin, M.I. and A. Hauchecorne, Lidar sounding of the structure and dynamics of the middle atmosphere. A review of recent results relevant to transport processus, in "Transport processes in the middle atmospheren, Reidel publishing Company, 1987.

Ebel, A., Contributions of gravity waves to the momentum, heat and turbulent energy budget of the upper mesosphere and lower thermosphere, $\mathrm{J}$. Atmos. Terr. Phys, 46, 727-737, 1984.

Hauchecorne, A. and M.L. Chanin, Density and temperature profiles obtained by lidar between 30 and $70 \mathrm{~km}$, Geophys Res. Letters, 7 , 564-568, 1980.

Holton, J.R., The role of gravity wave induced drag and diffusion in the momentum budget of the mesosphere, J.Atmos. Sci., 39, 791-799, 1982.

Iindzen, R.S., Turbulence and stress owing to gravity wave and tidal breakdown, $J$. Geophys. Res,, 86, 9707-9714, 1981.

Matsuno, T., A quasi one-dimensional model of the middle atmosphere circulation interacting with internal gravity waves, J. Meteor. Soc. Japan, $60,215-226,1982$.

Meek, C.E., I.M. Reid and A.H. Manson, Observations of mesospheric wind velocities. II. Cross-sections of power spectral density for $48-8 \mathrm{~h}, 8-1 \mathrm{~h}, 1 \mathrm{~h}-1$ min over $60-110 \mathrm{~km}$ for 1981 , Radio Science, 20, 1383-1402, 1985.

Schmidiln, F.J., Temperature inversions near $75 \mathrm{~km}$, Geophys. Res. Letters, 3, 173-176, 1976.

Schoerberl, M.R. and D.F. Strobel, The zonally averaged circulation of the middle atmosphere, J. Atmos. Sc1, 35, 577-591, 1978.

Schoerber1, M.R. and D.F. Strobel and J.P. Apruzese, A numerical model of gravity wave breaking and stress in the mesosphere, J. Geophys Res. , 88, 5249-5259, 1983.

Thomas, R.J., C.A. Barth and S. Solomon, Seasonal variations of ozone in the upper mesosphere and gravity waves, Geophys, Res, Letters, 11, 673-676, 1984.

Vincent, R.A. and D.C. Fritts, A climatology of gravity wave motions in the mesopause region at Adelaide, Australia, J, Atmos, Sci, 44, $748-760,1987$. 